02,05

\title{
Механизм формирования критического тока высокотемпературных сверхпроводников, содержащих сквозные микроскопические дефекты
}

\author{
(C) А.Н. Максимова, В.А. Кашурников, А.Н. Мороз, И.А. Руднев
}

Национальный исследовательский ядерный университет „МИФИ“, Москва, Россия

E-mail: anmaksimova@mephi.ru

Поступила в Редакцию 6 сентября 2020 г.

В окончательной редакции 6 сентября 2020 г.

Принята к публикации 8 сентября 2020 г.

Выполнен расчет критического тока модельного высокотемпературного сверхпроводника (ВТСП) с дефектами в виде сквозных отверстий (антиточками) с характерным размером больше или порядка глубины проникновения магнитного поля. Для этого в модель слоистого ВТСП введены подпроцессы, эквивалентные захвату отверстием магнитного потока и рождению вихря у границы отверстия. Показано, что учет данных подпроцессов приводит к появлению физического механизма, позволяющего корректно описать немонотонную зависимость критического тока от характерного размера антиточки, аналогичную наблюдаемой в эксперименте. Расчеты выполнены для чистого сверхпроводника и сверхпроводника, содержащего наноразмерные центры пиннинга. Показано, что наличие наноразмерных центров пиннинга наряду с антиточками не изменяют качественную картину влияния радиуса антиточки на характер пиннинга магнитного потока и поведение критического тока в ВТСП.

Ключевые слова: ВТСП, пиннинг, вихри Абрикосова, антиточки, метод Монте-Карло.

DOI: 10.21883/FTT.2021.01.50399.186

\section{1. Введение}

Несмотря на огромное число проведенных исследований, задача улучшения транспортных и магнитных характеристик сверхпроводников второго рода попрежнему представляет немалый фундаментальный и практический интерес. Одной из таких ключевых характеристик является плотность критического тока $j_{c}$. Наиболее распространенным способом повышения критического тока является создание искусственных центров пиннинга, препятствующих движению магнитного потока в сверхпроводнике, приводящего к появлению напряжения. Традиционными способами искусственного усиления пиннинга являются введение наноразмерных добавок (см., например, недавнюю работу по увеличению критического тока в ВТСП лентах второго поколения [1] и ссылки в ней), а также создание радиационных дефектов путем облучения ВТСП ионами высоких энергий, нейтронами и ударным плазменным воздействием [2-9]. При этом в сверхпроводящем материале формируются дефекты с характерным размером порядка длины когерентности, которые могут являться эффективными центрами пиннинга. В последнее время появилась новая технологии создания центров пиннинга в ВТСП-композитах. Она заключается в формировании в сверхпроводящем слое системы сквозных отверстий микронного масштаба - антиточек с помощью воздействия фемтои пикосекундными лазерными импульсами [10,11]. Такие дефекты, в силу своего диаметра порядка нескольких микрометров, не являются центрами пиннинга для оди- ночного вихря, так как значительно превосходят его по размеру. Однако множественный пиннинг вихрей Абрикосова может эффективно реализовываться по краю такого дефекта на границе сверхпроводящей и несверхпроводящей областей. В работах $[10,11]$ были представлены результаты экспериментальных исследований, не только демонстрирующих возможность повышения критического тока путем создания микроотверстий, но также устанавливающих немонотонность зависимости критического тока от радиуса отверстий. Масштабные экспериментальные исследования, направленные на выяснение механизма немонотонности критического тока от размера таких дефектов, как и определение оптимальных параметров системы дефектов, приводящих к максимальному повышению критического тока, связаны с известными практическими трудностями. Вместе с тем подобные исследования можно провести с помощью численного моделирования, в частности, с помощью метода Монте-Карло. Авторами настоящей работы на основе алгоритма Монте-Карло был развит и применен для различных случаев метод, позволяющий моделировать вихревую решетку в сверхпроводнике, находящемся в магнитном поле или под воздействием транспортного тока [12-17]. Особенности метода не позволяют моделировать образцы, размерами превосходящие несколько $\mu \mathrm{m}$, но, поскольку исследуемая система является частью объемного сверхпроводника, то, усредняя результаты идентичных расчетов, можно получить средний отклик всего образца. В работе [18] с использованием метода Монте-Карло было проведено моделирование критиче- 
ского тока и динамики вихревой системы Абрикосова в ВТСП с дефектами в виде отверстий. Однако полученные результаты не показали наличия немонотонности на зависимости критического тока от размера дефектов, что противоречило имеющимся экспериментальным данным [10,11]. В настоящей работе мы модифицировали модель, введя дополнительные процессы, описывающие захват отверстием магнитного потока и рождение вихря у границы отверстия. В результате удалось показать, что такой дополнительный механизм приводит к немонотонной зависимости критического тока от размеров отверстий, аналогичной наблюдаемой на эксперименте.

\section{2. Метод расчета}

Расчеты выполнены методом Монте-Карло в рамках модели слоистого ВТСП [12-19]. Вихревая нить в слоистом ВТСП может быть представлена в виде стопки плоских взаимодействующих вихрей (пэнкейков). Потенциал Гиббса системы вихрей, необходимый в расчете, состоит из собственной энергии вихрей, энергии их попарного взаимодействия, энергии взаимодействия с мейсснеровским и транспортным током, границей и центрами пиннинга [12-17]. В двумерной модели, использованной в данной работе, рассматривается один сверхпроводящий слой и пренебрегается межслоевым взаимодействием пэнкейков. Такой подход оправдан в слабоанизотропном ВТСП, когда пэнкейки в соседних слоях полностью скоррелированы и вихревая нить движется как целое. Также подход оправдан при сильной анизотропии, когда наблюдается 3D-2D-переход и один слой представляет средний отклик всего образца. В нашей работе в модель в качестве центров пиннинга вводятся субмикронные отверстия, образующие периодическую решетку. Как уже отмечалось, попытка ввести в модель такие центры пиннинга была предпринята в работе [18], где вихри могли закрепляться на краях отверстия. Расчеты, выполненные в [18], показывали монотонный рост критического тока с увеличением радиуса отверстия (при фиксированном расстоянии между центрами отверстий), что не соответствовало эксперименту. Однако, когда радиус отверстия превосходит глубину проникновения магнитного поля $\lambda$ в сверхпроводник (характерный размер вихря по круговым токам, его формирующим), становится возможным захват магнитного потока в отверстии, так что в отверстии оказывается отличное от нуля магнитное поле. Захваченный магнитный поток в макроскопических дефектах типа антиточек наблюдался экспериментально (см, например, [20] и ссылки в ней). Вокруг отверстия, захватившего магнитный поток, текут мейсснеровские токи, аналогичные токам у плоской границы. Также по достижении полем в отверстии критической величины возможно рождение вихря у края отверстия. Введем в модель подпроцессы, эквивалентные указанным. Взаимодействие вихря с отверстием складывается из взаимодействия с экранирующим током и собственным отражением от искривленной границы. Соответственно, при отсутствии захваченных вихрей в отверстии вихри притягиваются к нему, при наличии захваченного магнитного потока мейсснеровский ток отталкивает вихри от отверстия. Для корректного моделирования такой системы нужно ввести взаимодействие с мейсснеровским током вокруг отверстия и с отражением вихря от границы отверстия, уход вихря в дырку, что приводит к захвату потока, и рождение вихря вблизи границы отверстия. Однако введение мейсснеровского тока вокруг отверстия в расчет Монте-Карло связано с существенными трудностями. В частности, неясно, как выглядит профиль потенциала для вихря, взаимодействующего с токами вокруг отверстия и у плоской границы сверхпроводника. Поэтому нами сделано следующее модельное приближение.

Если радиус отверстия $R_{h}$ меньше лондоновской глубины проникновения, то отверстие описывается как круглая область, в которую не могут попасть вихри. Это можно моделировать введением бесконечно большой энергии внутри отверстия. Если $R_{h}>\lambda$, в отверстие могут заходить вихри. Вблизи края отверстия энергия имеет вид

$$
U_{\mathrm{pn}}=-\alpha \frac{1}{1+r_{i j} / \xi} \exp \left(-\frac{r_{i j}}{2 \xi}\right),
$$

где $r_{i j}$ - расстояние до края отверстия.

Такой подход моделирует притяжение вихрей к границе дырки. Также примем, что вихри, захваченные дыркой, обычным образом взаимодействуют с остальными, с мейсснеровским током и со своим отражением от границы образца. Это моделирует экранирующий ток вокруг отверстия.

\section{3. Результаты расчетов}

На рис. 1 показано распределение магнитного поля, создаваемого вихрями. Для наглядности также показано магнитное поле вихря в области антиточки. Для исключения искажений вихревой картины, вызванных взаимодействием вихрей противоположных знаков, вихревые картины показаны для случая перемагничивания внешним магнитным полем, а не полем транспортного тока, который присутствует при расчете вольт-амперных характеристик. Как легко видеть из вихревых распределений, полученных в результате расчета, вихри закрепляются на краях отверстия, при увеличении радиуса отверстия количество вихрей на краях увеличивается, и, начиная с определенного радиуса, происходит захват вихрей.

На рис. 2, а показана серия вольт-амперных характеристик образца с 16 отверстиями, рассчитанная в предположении, что имеет место только захват вихрей антиточкой. Это не меняет принципиально результатов работы [18], где имеет место только пиннинг вихрей на границе отверстия. Для сравнения на рис. 2, $b$ показана серия BAX при тех же параметрах, но с учетом рождения вихря у границы отверстия. Видно (см. также 

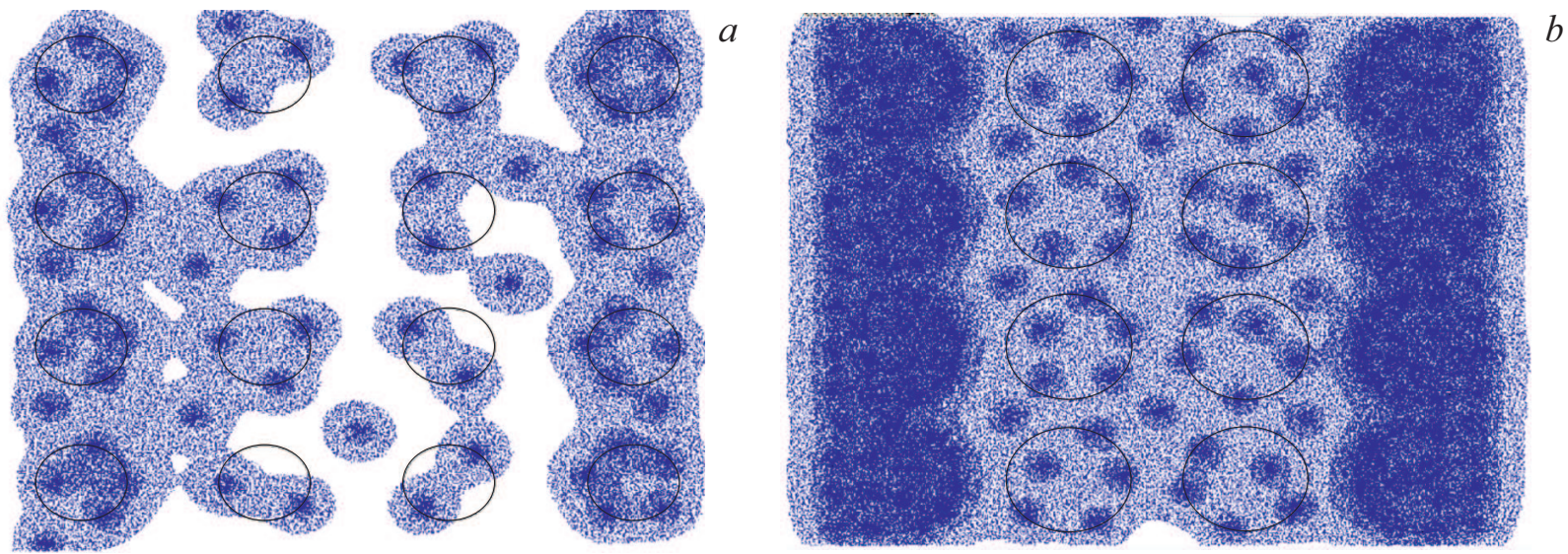

Рис. 1. Вихревые конфигурации для образца с различными радиусами антиточек: $\left.a) R_{h}=350 \mathrm{~nm}, b\right) R_{h}=500 \mathrm{~nm}$. Яркость изображения соответствует величине локальной магнитной индукции, границы антиточек показаны в виде черных кругов. На рис. $b$ ) видны вихри, захваченные отверстиями. Глубина проникновения магнитного поля $\lambda=180 \mathrm{~nm}$.
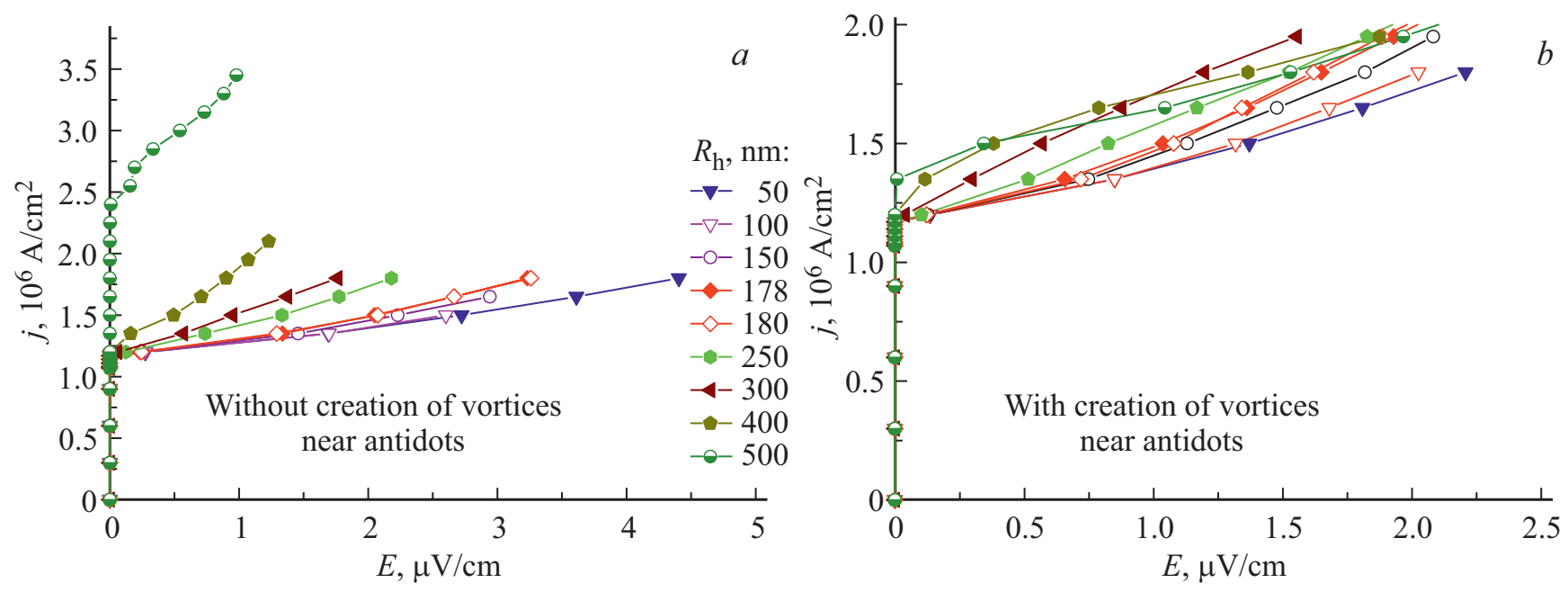

Рис. 2. ВАХ образца с 16 антиточками различного радиуса. а) Случай, когда рождение вихрей на границе отверстий не учитывалось, $b$ ) рождение вихрей на границе отверстий учитывалось.
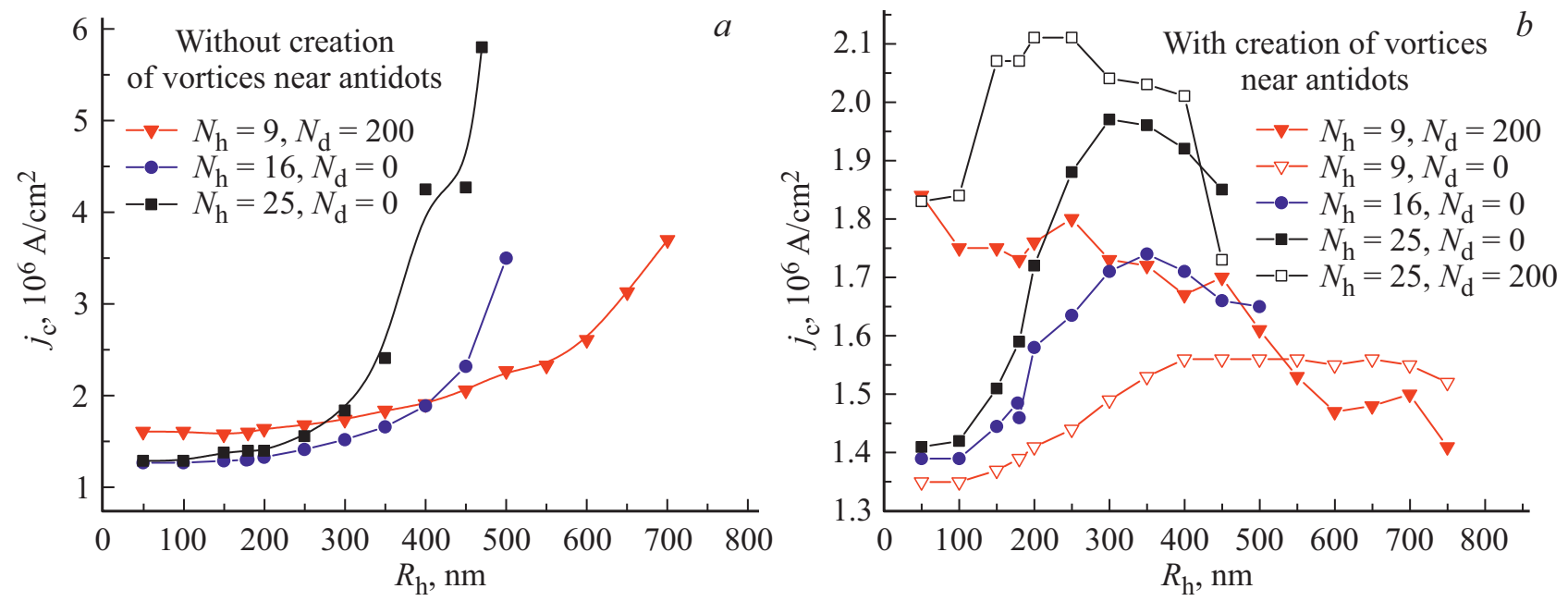

Рис. 3. Зависимости $j_{c}$ от радиуса отверстий без учета $(a)$ и с учетом $(b)$ рождения вихрей на границах отверстий. Данные приведены при различном радиусе отверстий. $N_{\mathrm{d}}-$ количество дополнительных наноразмерных дефектов. 
pис. $3, a)$, что при отсутствии эффектов рождения вихря, как и в [18], критический ток растет с ростом радиуса дефекта. Это связано с тем, что вихри, закрепленные на границе дефекта, экранируют новые вихри, входящие в образец, и эта экранировка увеличивается с уменьшением расстояния между вихрями на границах ближайших соседних отверстий.

Введем подпроцесс, эквивалентный рождению вихря у границы, - „выход“ захваченного вихря из отверстия. Зависимость критического тока от радиуса дефекта в этом случае не показывает резкого роста (рис. $3, b$ ), имеет слабо выраженный максимум, что качественно отражает экспериментальные результаты. Это позволяет утверждать, что механизм немонотонных зависимостей критического тока от радиуса антиточки, наблюдаемые экспериментально, может быть обусловлен возрастающей ролью процессов рождения вихрей у отверстий, захвативших магнитный поток, что приводит к более эффективному продвижению вихрей к центру образца. Заметим, что в $[10,11]$ максимум критического тока наблюдается на других масштабах отверстий. Однако в наших расчетах, как нетрудно видеть, максимум $j_{c}$ обусловлен не радиусом дефекта, когда становится разрешен „выход“ вихря из него, а соотношением между радиусами отверстий и расстоянием между ними. При этом соотношении эффекты „выхода“ вихрей из отверстия начинают преобладать над экранировкой, осуществляемой закрепленными на краях отверстия вихрями. При введении в расчет обычных, наноразмерных центров пиннинга, наряду с имеющимися антиточками, результаты качественно не меняются (см. рис. $3, b$ ).

\section{4. Заключение}

С помощью моделирования методом Монте-Карло качественно воспроизведены экспериментально наблюдаемые $[10,11]$ немонотонные зависимости плотности критического тока от радиуса субмикронных отверстий - антиточек в высокотемпературном сверхпроводнике. Показано, что механизм, определяющий наличие максимума $j_{c}$ при некотором радиусе антиточки обусловлен процессами рождения вихря у границы отверстия. Результата расчета могут быть применены к реальному эксперименту, т.к. показывают максимум критического тока при определенном соотношении радиуса антиточек и расстояния между их центрами. При одновременном увеличении линейных размеров образца и дефектов результаты расчета качественно не изменятся, что при соответствующем масштабировании может быть использовано для анализа конкретных экспериментальных данных.

\section{Финансирование работы}

Исследование выполнено при финансовой поддержке РФФИ в рамках научного проекта № 20-08-00811. А.Н. Мороз благодарит РФФИ за финансовую поддержку в рамках научного проекта № 19-32-90279.

\section{Конфликт интересов}

Авторы заявляют, что у них нет конфликта интересов.

\section{Список литературы}

[1] P. Degtyarenko, S. Gavrilkin, A. Tsvetkov, N. Mineev, I. Rudnev, A. Ovcharov, V. Chepikov, S. Lee, V. Petrykin, A. Molodyk. Supercond. Sci. Technol. 33, 045003 (2020).

[2] N. Haberkorn, S. Suarez, P.D. Perez, H. Troiani, P. Granell, F. Golmar, J.-H. Lee, S.H. Moon. Physica C 542, 6, (2017).

[3] S. Eley, M. Leroux, M.W. Rupich, D.J. Miller, H. Sheng, P.M. Niraula, A. Kayani, U. Welp, W.-K. Kwok, L. Civale. Supercond. Sci. Technol. 30, 015010 (2017).

[4] N. Haberkorn, S. Suarez, J.-H. Lee, S.H. Moon, H. Lee. Solid State Commun. 289, 51 (2019).

[5] T. Sueyoshi, T. Kotaki, Y. Uraguchi, M. Suenaga, T. Makihara, T. Fujiyoshi, N. Ishikawa. Physica C 530, 72 (2016).

[6] K.J. Leonard, F.A. List III, T. Aytug, A.A. Gapud, J.W. Geringer. Nucl. Mater. Energy 9, 251 (2016).

[7] D.X. Fischer, R. Prokopec, J. Emhofer, M. Eisterer. Supercond. Sci. Technol. 31, 044006 (2018).

[8] J. Emhofer, M. Eisterer, H.W. Weber. Supercond. Sci. Technol. 26, $035009(2013)$.

[9] Л.Х. Антонова, И.В. Боровицкая, П.В. Горшков, Е.И. Демихов, Л.И. Иванов, О.Н. Крохин, Г.Н. Михайлова, А.П. Менушенков, В.Я. Никулин, А.В. Огинов, А.И. Подливаев, С.В. Покровский, И.А. Руднев, А.В. Троицкий. Докл. АН 428, 471 (2009).

[10] S.V. Pokrovskii, O.B. Mavritskii, A.N. Egorov, N.A. Mineev, A.A. Timofeev, I.A. Rudnev. J. Phys. Conf. Ser. 941, 012078 (2017).

[11] S.V. Pokrovskii, O.B. Mavritskii, A.N. Egorov, N.A. Mineev, A.A. Timofeev, I.A. Rudnev. Supercond. Sci. Technol. 32, 075008 (2019).

[12] I.A. Rudnev, V.A. Kashurnikov, M.E. Gracheva. Physica C 332, 383 (2000).

[13] М.Е. Грачева, В.А. Кашурников, И.А. Руднев. Письма в ЖЭТФ 66, 269 (1997).

[14] Д.С. Одинцов, И.А. Руднев, В.А. Кашурников. ЖЭТФ 132, 287 (2007).

[15] В.А. Кашурников, А.Н. Максимова, И.А. Руднев. ФТТ 56, 861 (2014).

[16] Д.С. Одинцов, И.А. Руднев, В.А. Кашурников. ЖЭТФ 130, 77 (2006).

[17] I.A. Rudnev, D.S. Odintsov, V.A. Kashurnikov. Phys. Lett. A 372, 3934 (2008).

[18] A.N. Moroz, A.N. Maksimova, V.A. Kashurnikov, I.A. Rudnev. IEEE Trans. Appl. Supercond. 28, 8000705 (2018).

[19] W.E. Lawrence, S. Doniach. In: Proceedings of LT 12. Kyoto, 1970 / Ed. E. Kanda. Keigaku, Tokyo (1971). P. 361.

[20] C. Xue, J.Y. Ge, A. He, V.S. Zharinov, V.V. Moshchalkov, Y.H. Zhou, A.V. Silhanek, J. Van de Vonde. Phys. Rev. B 97, 134506 (2018).

Редактор К.В. Емцев 